\title{
REVIEWS.
}

\section{THE PATHOLOGY OF HIGH} ALTITUDE CLIMATE.

With Contributions to the Climatology

of Highland Regions and to the

Constitution of High Altitude Inhabitants.

By A. Loewy, Late Professor of the University, Berlin; Emeritus Director of the Swiss Institute of High Altitude Physiology and Tuberculosis Research and E. WITTKOWER, M.D. (Berlin), L.R.C.P \& S. (Edinburgh), Formerly Lecturer of the University, Berlin; Formerly Research Worker at the Swiss Institute of High Altitude Physiology; Halley Stewart Research Fellow of the Tavistock Clinic, London. Oxford University Press, London; Humphrey Milford. 1937. Price $12 / 6$ net.

Here is a book which was needed, for the literature concerning the effects, good and bad, of high altitude has been so disseminated and difficult to bring together that this book has done a real service in this respect alone. As the authors rightly say in their introduction, tropical climates have been adequately dealt with but high altitude climate has received little attention.

The first chapter deals with the meteorology of these climates, and although it tends to be rather incomplete, it does bring together most of the salient facts.

The best chapter in the book deals with the effect of high altitude climate on the constitution of the inhabitants and contains more useful and abiding information in its 30 pages than can be found in the 100 pages devoted to the diseases occurring in high altitude countries.

Of particular interest is the relation of chest circumference to seated height, and the figures for the so-called thoracic index at Davos, even though they are incomplete.

It seems as if the figures for higher altitudes than 16,000 feet would be of interest, as this level does not bring into sufficient prominence some of the effects of altitude.

The chapter on diseases contains such figures as are available, but there is little profit in discussing diseases like measles and whooping-cough; the section on tuberculosis is fairly written and bears out the impression of most clinicians of the relative effect of altitude on pulmonary and non-pulmonary tuberculosis.

The book ends with a chapter on the curative effects of mountain climate.

The effect of altitude is a matter which, for various reasons, is becoming increasingly important, and is being extensively studied, and the mechanism of acclimatization is of great interest to many people. The phenomena observed in low pressure chambers experimentally might perhaps have had a chapter, although these have no relation to climate and might have made the book too bulky.

Drs. Loewy and Wittkower have written a good book and still more importantly, a timely book, and are to be congratulated on their work.

\section{ELECTROCARDIOGRAPHY.}

\section{(Second Edition.)}

By Chauncey C. Maher, B.S., M.D., Assistant Professor of Medicine, Northwestern University and the Montgomery Ward Medical Clinics; Attending Internist at the Cook County Infirmary and the Cook County Hospital and the Passavant Memorial Hospital, Chicago, Illinois. Baillière, Tindall \& Cox. 1937. Price $18 /-$.

Electrocardiography is gradually coming to occupy the position which it should rightly hold, the handmaid, not of the cardiologist alone, but of every practising physician who diagnoses and treats heart conditions.

Dr. Chauncey Maher introduces his book with the suggestion that this desirable end will be furthered if each physician possesses a systematic classification, a clinical knowledge of the arrhythmias, and an acquaintance with the cardiac conduction system, and he suggests, very wisely, that the latter is best obtained by actual dissection.

He opens his book with a general chapter on the clinical concepts of heart disease in general and goes on to study the arrhythmias and the conduction system. The remainder of the book is devoted to the electrocardiograph, showing diagrams, some $\mathrm{X}$-rays and tracings of each condition. 
The classification of heart disease originated by the Heart Committee of the Tuberculosis and Health Association of New York and approved by the American Heart Association, is divided into four groups and these are designated Etiological, Anatomical, and Physiological diagnosis, and Functional capacity; this classification forms the basis of nomenclature for the book.

Etiological diagnosis includes all the basic diseases, if you can call them so, which are commonly followed by heart disease.

Anatomical diagnosis includes all the various parts of the cardiac apparatus with the disasters which may befall them, and physiological diagnosis includes all the various types of disorders of rhythm, with the addition of the Stokes-Adams and anginal syndromes, and incompetency of the various valves.

Function capacity is divided into three stages according to the amount of work which the patient can do.

It would perhaps have been simpler if " Anatomical diagnosis" had been labelled " Structural damage" and "Physiological diagnosis" had been labelled "Resultant abnormalities of function."

"Clinical concepts of the arrhythmias" the second chapter has probably been added to make the book complete, but it is very difficult to deal with this subject in four and a half pages and it would have probably been better to omit it.

The electrocardiograph is described and the simple electrical laws of muscular contraction. For nearly all the disorders of rhythm there is a special diagram of the heart with a sample lead underneath to illustrate the mechanism involved.

In spite of all the obvious trouble that has been taken it is doubtful whether the explanations given will be clear to the beginner, and it is evidently for him that the book is written. It might have been better to have magnified one complex from each tracing and shown that in a small inset with the waves lettered, as it is many of the tracings have no interest for the cardiologist, but are nevertheless not easily understandable by the novice.

Some of the captions are not written with proper care, for instance " an isoelectric T wave " is a frank impossibility, the $T$ wave is due to a change of potential and if there is no change there is no "wave."

A complicated method of computing " axis deviation" is described which necessitates three electrocardiographs being simultaneously attached to a patient, but there is little value in attaching detailed, complicated and unproved material to a book which is written for beginners.

Too much importance should not be attached to these points, however, for the general conception of the book, its layout, and its plan are really excellent. Enormous trouble has been taken to make sure that each tracing represents accurately the condition it is intended to portray, and the book will serve admirably the purpose which Dr. Maher had in mind when he wrote it.

\section{HISTORICAL NOTES ON PSYCHIATRY.}

By J. R. Whitwell. H. K. Lewis \& Co., Ltd. London. 1936. Price 10/6.

An account of mental disorder considered from the angle of historical research cannot fail to interest. True, there always exists a minority of medical men, who are out of patience with any "harking-back" to the past, as a line of investigation. To such Dr. Whitwell's book will be devoid of meaning. Nevertheless, to those physicians, psychiatrists and others who feel that a study of the foundations of our knowledge can contribute something of value, this little work will appeal. An important section of the book is made up of translated excerpts from the works of various classical and mediæval writers, dealing with mental affections.

CIVILIZATION AND DISEASE.

By C. P. Donnison, M.D. Baillière, Tindall \& Cox. 1937. Price 10/6.

Dr. Donnison's thesis is that much of the disease to which civilized man is subject is due to his inability to accommodate himself to his most complex environment. In support of this view he contrasts, in the first place, the maladies that afflict primitive man, of whom he has had a large experience in Africa, with those that are met with in the case of his civilized brother. 